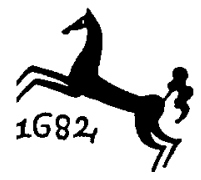

Germanistische Abhandlungen

Untersuchungen zur Theorie des Romans

von Hegel bis zum Naturalismus 
FRANZ RHOSE

\section{Konflikt und Versöhnung}

Untersuchungen zur Theorie des Romans von Hegel bis zum Naturalismus 
GERMANISTISCHE ABHANDLUNGEN 47

CIP-Kurztitelaufnahme der Deutschen Bibliothek

Rhöse, Franz

Harmonie und Versöhnung: Unters. zur Theorie

d. Romans von Hegel bis zum Naturalismus. -

1. Aufl. - Stuttgart: Metzler, 1978.

(Germanistische Abhandlungen; 47)

ISBN 978-3-476-00376-8

DOI 10.1007/978-3-476-03086-3

ISBN 978-3-476-03086-3 (eBook)

(C) 1978 Springer-Verlag GmbH Deutschland

Ursprünglich erschienen bei J. B. Metzlersche Verlagsbuchhandlung

und Carl Ernst Poeschel Verlag GmbH in Stuttgart 1978 
Diese Arbeit lag Ende 1976 unter dem Titel „Konflikte und ihre Lösungen. Untersuchungen zur Diskussion von Roman und Romanschluß im neunzehnten Jahrhundert « in einer umfangreichen Fassung der ehem. Philosophischen Fakultät II der Universität München als Dissertation vor. Für die Anregung des Themas und die Betreuung der Arbeit über Jahre hinweg möchte ich Herrn Professor Walter Müller-Seidel herzlich danken.

München im Oktober 1977

F. Rh. 


\section{INHALTSVERZEICHNIS}

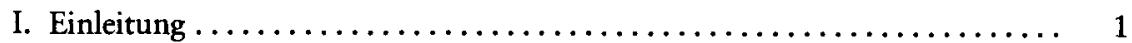

Teil I: Ästhetik und Roman

II. Zwischen Bildungsroman und Desillusionsroman - Zur Ambivalenz der Kategorien für Roman und Romanschluß in Hegels Ästhetik ........... 4

1. Die Stellung des Romans im System der Hegelschen Ästhetik ........ S

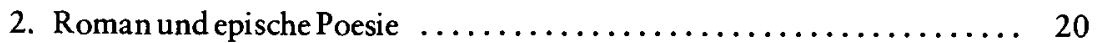

III. Bildungsroman oder Sozialroman - Fr. Th. Vischers Romanbegriff zwischen Vormärz und bürgerlichem Realismus $\ldots \ldots \ldots \ldots \ldots \ldots \ldots \ldots \ldots, 26$

1. Vom Bildungsroman zur Diskussion um den Sozialroman .......... 27

2. Zur Kritik des Sozialromans und seiner Lösungen - die Sue-Rezeption in Deutschland ............................... 31

3. Gesellschaftsanalyse und Möglichkeiten des Romans - Vischers Ästhetik

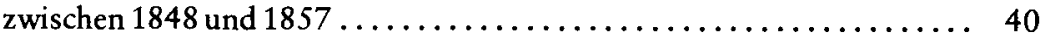

4. Die Rückkehr zum Bildungsroman - Epos und Romantheorie im sechsten Band der Ästhetik (1857) .......................... 43

IV. Harmonie und Versöhnung -Umrisse einer christlichen Ästhetik . . . . . . 51

1. Romanschluß und sittliche Weltordnung - Zur christlichen Ästhetik bei Moritz Carriere ........................... 51

2. Schönheit und Harmonie als Weltgesetz - Die theistische Begründung der

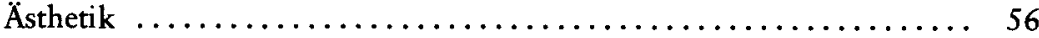

3. Zwischen christlicher und psychologischer Begründung harmonischer

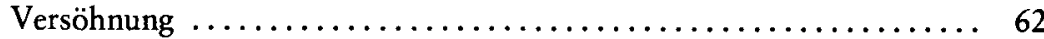

V. Pessimismus-Zur heroisch-tragischen Ästhetik der Gründerzeit . . . . . . . 67

1. Gründerzeitliche Antithesen - Das Tragische und das Glück ........ 68

2. Asthetische Erziehung oder Sieg der Sittlichkeit? ............. 73

3. Konflikt und tragische Lösung - Hartmanns metaphysischer Pessimismus 74

4. Pessimismus und Romanschluß -Zur Rezeption Iwan Turgenjews ..... 78 
VI. Roman und Romanschluß in der »Poetik « des neunzehnten Jahrhunderts . . $\quad 85$

1. Schulpoetik und Roman - Versuch einer Erkundung ........... 85

2. Spannung und Lösung - Probleme des Romanschlusses in der Poetik Rudolf Gottschalls ............................ 89

3. Sieg der Idee -Zur Theorie des liberalen Zeitromans ............ 94

Teil II: Autorenpoetik und Romandiskussion

VII. Offener Romanschluß und historische Perspektive - Zur Diskussion eines deutschen Sozialromans im Umkreis Karl Gutzkows . . . . . . . . . . 100

1. Der Roman als politische Waffe - Romanbegriff und Romanpraxis Karl

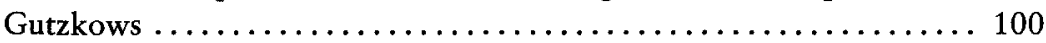

2. »Fortsetzung folgt « - die Diskussion der 50er Jahre über den Schluß der Ritter vom Geiste .............................. 110

VIII. Konflikte und sittlich-harmonische Lösungen - der bürgerliche Optimismus der Grenzboten . .................................. 117

1. "Harmonie der gestörten Verhältnisse « - Dramenschluß und Romanschluß in Freytags Literaturmodell . . . . . . . . . . . . . . . . . . 119

2. Soll und Haben - Entstehung und Rezeption eines exemplarischen Bil-

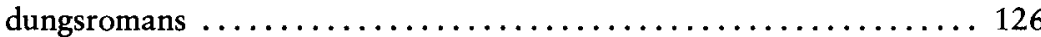

3. Wirklichkeitsbegriff und künstlerischer Abschluß - Julian Schmidts Begründung des bürgerlichen Bildungsromans ............. 134

4. Dissonanz und Harmonie-Konfliktlösungsmodelle ............ 139

IX. Zur Ablehnung des gesellschaftskritischen Zeitromans im frühen Realismus-die Romanstudien Otto Ludwigs . . . . . . . . . . . . . 146

1. Ludwigs Poesiebegriff und die Folgen für den Roman ........... 147

2. Kritik an den $»$ Tendenzgeschichten $"$ von Dickens ............. 149

3. Otto Ludwigs Romanmodell-der positive Tendenzroman ......... 152

X. Antizipierte Harmonie ohne gesellschaftliche Versöhnung - das Beispiel

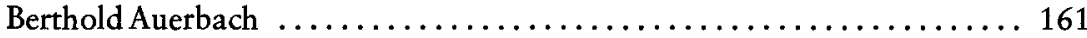

1. Der gebildete Bürger - Bewußtseinsgeschichtliche Voraussetzungen eines

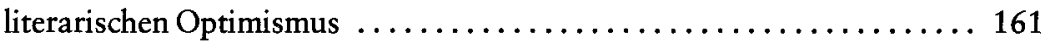

2. Das Harmoniekonzept in der literarischen Theorie-Schrift und Volk ... 163

3. Konflikte und ihre Lösungen -die Erwartungen der Literaturkritik . . . . . 168

4. Integrierte Tendenz und ungelöste Konflikte - Auerbach zwischen Vormärz und Gründerzeit $\ldots \ldots \ldots \ldots \ldots \ldots \ldots \ldots \ldots \ldots \ldots \ldots \ldots \ldots \ldots \ldots \ldots \ldots$ 
XI. Versöhnende Weltanschauung und gesellschaftliche Konflikte - Zur Theorie des Romans bei Friedrich Spielhagen . . . . . . . . . . . . . . 176

1. Die versöhnende Kraft des Humors - Möglichkeiten und Grenzen des humoristischen Romans $\ldots \ldots \ldots \ldots \ldots \ldots \ldots \ldots \ldots \ldots \ldots \ldots \ldots \ldots \ldots$

2. Gesellschaftliche Funktion und ästhetische Rechtfertigung des Romans .. 180

3. Konflikte und Lösungsversuche im politischen Zeitroman . . . . . . . 187

4. Zur Rezeption der Romanschlüsse Friedrich Spielhagens ........... 193

XII. Zur Poetik von Roman und Romanschluß in der Epoche des Naturalismus . . 205

1. Paradigmawechsel im Bewußtsein der Zeitgenossen ............ 205

2. Die Ablehnung des alten Schlußmodells durch die Naturalisten . . . . . . 207

3. Rezeptionsbedingungen tragischer Schlüsse -das Beispiel Kein Hüsung . . 209

4. Offener Schluß oder sozialistische Zukunftsperspektive .......... 214

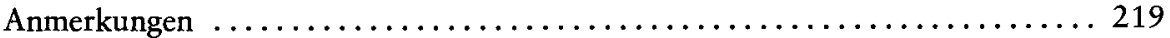

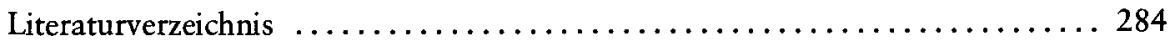

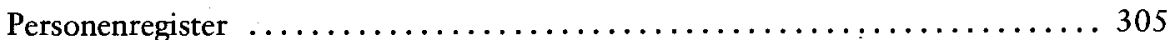

